\title{
A surgical study of serological markers such as C-reactive protein and interleukin 6 in response to postoperative infection in patients with open fractures in a tertiary care hospital
}

\author{
J. P. V. Jebaraj' ${ }^{1}$ B. Ezhil Rajan ${ }^{1 *}$, N. Ashok Viswanath ${ }^{2}$, R. Preethy ${ }^{2}$
}

\begin{abstract}
${ }^{1}$ Department of Orthopedics, ${ }^{2}$ Department of Clinical Microbiology, Panimalar Medical College Hospital and Research Institute, Chennai, Tamil Nadu, India
\end{abstract}

Received: 09 October 2021

Revised: 02 February 2022

Accepted: 03 February 2022

\author{
*Correspondence: \\ Dr. B. Ezhil Rajan, \\ E-mail: orthoezhil@gmail.com
}

Copyright: () the author(s), publisher and licensee Medip Academy. This is an open-access article distributed under the terms of the Creative Commons Attribution Non-Commercial License, which permits unrestricted non-commercial use, distribution, and reproduction in any medium, provided the original work is properly cited.

\begin{abstract}
To study the response of C-reactive protein (CRP) and interleukin-6 (IL-6) to postoperative infection in patients with open fractures. Thirty patients with open fractures of extremities within 12 hours of injury were included in study. Blood samples were collected for Postoperative infection is a devastating complication of open fractures. The ideal investigation for early diagnosis of infection should be done before surgery and should be accurate, convenient to patient, cause minimal morbidity. Test such as CRP and IL-6 estimation is utilized in this study. CRP and IL 6 estimation on admission, second and fourth post-op day. All patients underwent surgery and reports evaluated. It was observed that CRP peak on post-op day 4 and IL 6 on postoperative day 2 in patients with infection before clinical evidence of infection. This prospective study includes 30 cases, followed up in ward for a week. Various factors regarding clinical presentation, findings of various investigations, operative treatment had been analyzed. The sensitivity of CRP in our study was $100 \%$, and specificity was $42 \%$. The persistent rise of CRP value seen within the infected group was statistically significant $(\mathrm{p}<0.05)$. The present clinical study of estimation of CRP and IL 6 to detect postoperative infection in patients after open fractures is an excellent diagnostic test for early detection and management of infection.
\end{abstract}

Keywords: Postoperative infection, Acute phase reactants CRP, IL-6, Open fractures

\section{INTRODUCTION}

Postoperative infection is a devastating complication of open fractures. Many of the diagnostic tests (culture of intraoperative specimens, histo-pathological study) cannot aid the surgeon with preoperative planning as the specimens are not obtained until a debridement is done. The ideal investigation for early diagnosis of infection should be done before operation and should involve a minimum number of tests, should be accurate, convenient to the patient, cause minimal morbidity, and costeffective. ${ }^{1} \mathrm{CRP}$ is a pentameric protein synthesized by the liver, whose level rises in response to inflammation of non-specific origin. There are various causes of an acute elevation of CRP. These include etiology of acute and chronic conditions, which can be infectious or noninfectious. CRP is one of the most consistently elevated and fastest reaching acute phase proteins and is therefore a useful marker for early diagnosis of infection. It is more specific than clinical signs alone. A single study detects inflammation, but serial CRP measurement gives best diagnostic information and useful for early detection of post operative infections. ${ }^{2,3}$ With no infection, CRP begins to decline, hours after uncomplicated surgery. CRP raises 4-6 hours post trauma, peaks at 24-48 hours and returns to baseline on day 3 . The effects of surgery and trauma on CRP levels seemed to be additive. Persistent elevation of CRP levels beyond post operative day 3 is associated with infections and itis dependable indicator of sepsis in trauma. IL-6 is one of the most important mediators of 
short-term phase response. Although it is a mediator of the physiologic short-term phase reaction to injury, excessive and prolonged post injury elevations are associated with infection. A post operative increase in CRP is associated with an increase in IL-6. However, CRP levels may be increased even when the inflammatory stimulus has stopped. Trauma causes rapid increase in IL-6 levels within 12 hours. It remains increased for 24 hours after injury. Then decreasing from their peak values during the next 24 hours. It was noted that patients with elevated IL 6 levels at 24-72 hours after surgery are at increased risk of postoperative infections. Due to its rapid normalization, measurement of serum IL 6 concentration may be useful to support the suspicion of infections. A normal CRP and IL-6 response to surgery and trauma without secondary risk may exclude the possibility of post-operative septic complications. Present clinical study was done to measure the levels of both CRP and IL6 in post-op patients with open fractures, in which infection can be detected early.

\section{CASE SERIES}

A prospective case study had been carried out after ethical clearance from institutional ethical committee, from December 2017 to December 2018, in the department of orthopaedics, Sree Balaji medical college and hospital, Chennai, India. Thirty patients, who presented with open fractures of upper and lower extremities within 12 hours of injury were included in the study with inclusion criteria as follows: Patients with open fractures, Patients between 20 to 60 years of age, both male and female patients. The exclusion criteria were patients with urinary tract infections, myocardial infarction, pneumonia and other clinically detectable infections. Patients included in the study were asked about history related to the nature of trauma and presence of any infections. Detailed general physical, clinical examination to assess for the presence of infections was done. All patients were admitted and investigated. Antero-posterior and lateral X-ray of the involved extremity were taken, diagnosis recorded and planned for emergency wound debridement and external fixation. Blood samples were collected using vacutainer serum collection tubes and the serum was separated and estimated for CRP and IL-6 on day of admission, second and fourth post operative day. Qualitative and semiquantitative determination of CRP in serum was done using methods such as qualitative and semi quantitative latex agglutination and using semi-automated nephelometry. IL-6 estimation was done using enzyme link immunosorbent assay (ELISA). All patients underwent surgery and reports were evaluated by standard statistical methods. Data entry was carried out in Microsoft excel and statistical analysis was carried out with SPSS software.

This prospective study includes 30 cases, followed up in ward for a week. Various factors regarding clinical presentation, findings of various investigations, operative treatment had been analyzed. Mean age was 35 years. Minimum age was 10 years and maximum age was 60 years. Male preponderance was more than female. The serum samples were tested for CRP and IL 6 concentrations preoperative, postoperative 2 and postoperative day 4 . Wound swabs were collected on postoperative days 2,4 and 6 . The preoperative CRP values of all 30 patients ranged from $<7 \mu \mathrm{g} / \mathrm{ml}$ to $21 \mu \mathrm{g} / \mathrm{ml}$ (mean $=8.45 \mu \mathrm{g} / \mathrm{ml}$ ). The preoperative CRP values by nephelometry ranged from $<3 \mathrm{mg} / \mathrm{L}$ to $112 \mathrm{mg} / \mathrm{L}$ (mean $31.89 \mathrm{mg} / \mathrm{L})$. The CRP values showed a rise on postoperative day 2 in both infected and non-infected patients. The mean CRP in patients with infection was $12.09 \mu \mathrm{g} / \mathrm{ml}$ (133.33 $\mathrm{mg} / \mathrm{L}$ by nephelometry) and in patients without infection it was $14.74 \mu \mathrm{g} / \mathrm{ml}(90.54 \mathrm{mg} / \mathrm{L}$ by Nephelometry) (Table 1), both were higher than their corresponding pre-op values. The CRP value on postoperative day 4 in patients without infection showed a significant decrease $(\mathrm{p}<0.05)$ from postoperative day 2 values range being $<7 \mu \mathrm{g} / \mathrm{ml}$ to $14 \mu \mathrm{g} / \mathrm{ml}$ with a mean of $8 \mu \mathrm{g} / \mathrm{ml}$ (Mean=17.63 $\mathrm{mg} / \mathrm{L}$ by nephelometry). In patients with infection there was persistent elevation of CRP ranging from $7 \mu \mathrm{g} / \mathrm{ml}$ to $28 \mu \mathrm{g} / \mathrm{ml}$ (mean $17 \mu \mathrm{g} / \mathrm{ml}$ ) higher than their postoperative day 2 values. The difference in CRP values on postoperative day 4 between infected and non-infected groups was statistically significant $(\mathrm{p}<0.05$ both in latex agglutination and nephelometry). The sensitivity of CRP in our study was $100 \%$, and specificity was $42 \%$. The persistent rise of CRP value seen within the infected group was statistically significant $p$ value of $<0.05$.

In the present study the preoperative mean IL 6 values in patients with infection was $415.18 \mathrm{pg} / \mathrm{ml}$ and in patients without infection it was $1122.24 \mathrm{pg} / \mathrm{ml}$ (Table 1), (Figure 1 and 2). The IL 6 values of postoperative day 2 in patients with infection showed a persistent elevation ranging from $190-4650 \mathrm{pg} / \mathrm{ml}$ (mean $689.72 \mathrm{pg} / \mathrm{ml}$ ), whereas in patients without infection the values dropped to $12-820 \mathrm{pg} / \mathrm{ml}$ (mean $145.47 \mathrm{pg} / \mathrm{ml}$ ) which was statistically significant $(p=0.039)$. IL 6 serum levels were significantly higher $(\mathrm{p}=0.030)$ in patients with infection than in those without infection. The postoperative day 4 IL 6 values in patients without infection ranged from $11.8 \mathrm{pg} / \mathrm{ml}$ (mean 49.46 $\mathrm{pg} / \mathrm{ml}$ ) and in patients with infection 33-420 pg/ml (mean $160.91 \mathrm{pg} / \mathrm{ml}$ ) progressively decreasing from their postoperative day 2 values. In our study, the sensitivity of the IL 6 test was $90 \%$ and specificity $100 \%$. The mean difference of IL 6 values between postoperative day 2 and postoperative day 4 within the infected group seen in our study was not statistically significant $(p=0.0226)$. This shows that the IL 6 which peaked on day 2 remained elevated on day 4 as well. We used culture of the discharge to diagnose infection. All 11 infected cases clinically showed evidence of local warmth, gaping in cases where the wound was primarily closed. In cases where wound was left open, discharge was present on day 6 which was bacteriologically confirmed. It was observed that CRP peak on postoperative day 4 and IL 6 on postoperative day 2 in patients with infection before clinical evidence of infection. 
Table 1: Mean values of pre-operative, post-operative days 2 and 4 of CRP and IL-6.

\begin{tabular}{|c|c|c|c|c|}
\hline Groups & & $\mathbf{N}$ & Mean & Standard deviation \\
\hline \multirow{2}{*}{ CRP Pre op } & Infected & 11 & 8.91 & 5.108 \\
\hline & Non infected & 19 & 8.00 & 3.972 \\
\hline \multirow{2}{*}{ CRP POD 2} & Infected & 11 & 12.09 & 7.063 \\
\hline & Non infected & 19 & 14.74 & 5.162 \\
\hline \multirow{2}{*}{ CRP POD 4} & Infected & 11 & 17.18 & 5.741 \\
\hline & Non infected & 19 & 8.42 & 4.168 \\
\hline \multirow{2}{*}{ IL 6 Pre op } & Infected & 11 & 415.18 & 877.611 \\
\hline & Non infected & 19 & 1122.26 & 1742.046 \\
\hline \multirow{2}{*}{ IL 6 POD 2} & Infected & 11 & 1057.91 & 1749.125 \\
\hline & Non infected & 19 & 145.47 & 175.453 \\
\hline \multirow{2}{*}{ IL 6 POD 4} & Infected & 11 & 160.91 & 125.277 \\
\hline & Non infected & 19 & 49.46 & 26.482 \\
\hline \multirow{2}{*}{$\begin{array}{l}\text { NEPH Pre op } \\
\text { CRP }\end{array}$} & Infected & 6 & 49.42 & 41.626 \\
\hline & Non infected & 13 & 14.37 & 16.383 \\
\hline \multirow{2}{*}{$\begin{array}{l}\text { NEPH POD } 2 \\
\text { CRP }\end{array}$} & Infected & 6 & 133.3333 & 111.899836 \\
\hline & Non infected & 13 & 90.5462 & 44.49171 \\
\hline \multirow{2}{*}{$\begin{array}{l}\text { NEPH POD } 3 \\
\text { CRP }\end{array}$} & Infected & 7 & 136.9857 & 147.13811 \\
\hline & Non infected & 13 & 17.6323 & 6.61731 \\
\hline
\end{tabular}

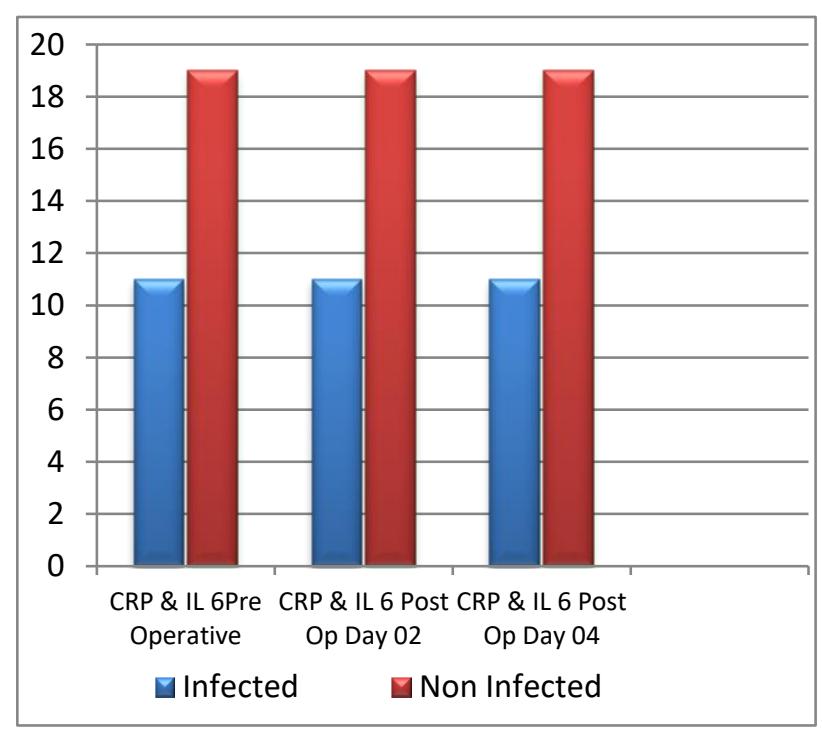

Figure 1: CRP and IL6.

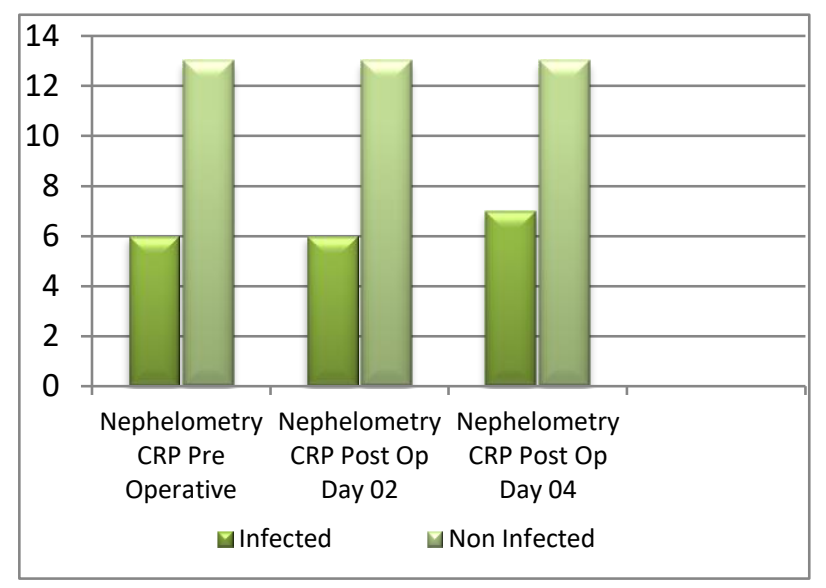

Figure 2: CRP-nephelometry.

\section{DISCUSSION}

Patients with post operative infection may present with systemic symptoms and signs compatible with sepsis, many present with features indistinguishable from the effects of surgery itself such as fever, tachycardia, and elevated white blood cell count. CRP is the archetypal acute phase protein is a marker of many infectious and non-infectious condition like bacterial infection, rheumatic fever, myocardial infarction, vascular disorders and renal transplant failure. The mean CRP in the study done by Kallio et al on closed tibial fractures was $8.7 \mathrm{mg} / \mathrm{L} .^{3}$ The increased preoperative CRP values seen in our study might be because it was done on open fractures and the severity of trauma is high in open fractures. Nevertheless, the important issue in the present study is not the starting value, but the magnitude of alteration in the values of the biologic markers in both groups postoperatively. Gupta et al showed a similar increase in CRP value on postoperative day 2 after elective orthopaedic procedures. ${ }^{4}$ Kragsbjerg et al also observed a peak CRP value 48-96 hrs after cardiac and gastro intestinal operations. ${ }^{5}$ Gupta et al observed that from third day CRP showed a sharp decline in all cases without infection and persistent rise beyond third day was consistent with sepsis. ${ }^{4}$ Tarik et al also showed that a CRP level on days 3 and 4 that is $>80 \%$ of day 2 correlated with infection detected clinically. ${ }^{2}$ CRP estimation in previous studies discusses its role in closed fractures and arthroplasty. In the present study, effect of trauma and the surgery both seemed to be additive. Hence, preoperative concentration of CRP was higher than that seen in other studies. IL-6 is a pleiotropic cytokine that functions as a proinflammatory and anti-inflammatory molecule. It is produced by stimulated macrophages and monocytes when tissue is injured. ${ }^{6}$ The serum IL 6 level in normal individuals is a $1 \mathrm{pg} / \mathrm{ml}^{7,8}$ Accumulating evidence indicates that the serum IL 6 level can be a valuable marker 
of inflammation in association with trauma, sepsis as well as after major cardiac and abdominal surgery. ${ }^{9-11}$ IL 6 concentrations exhibit more rapid increase and quicker return to normal values than either $\mathrm{C}$ reactive protein or the erythrocyte sedimentation rate, suggesting that IL 6 may be a superior indicator of postoperative infection. ${ }^{12} \mathrm{IL}$ 6 levels peak in the first 6-12 hours after surgery and fall back to their baseline range by $48-72$ hours post operatively, whereas the serum CRP and ESR typically, remain elevated over this time-span. Elevated IL 6 levels at 24-72 hours after surgery are at risk of postoperative infection. $^{13,14}$ The effect of surgery and infection on the plasma IL 6 concentration is additive. In the study done by Pul et al on IL 6 following knee and hip arthroplasy, the preoperative values were defined as $<10 \mathrm{pg} / \mathrm{ml}$. ${ }^{6}$ Jose et al studied the efficacy of IL 6 in predicting post operative infection following gastrointestinal surgery. ${ }^{15}$ The basal IL 6 concentration was defined as $12.5 \mathrm{pg} / \mathrm{ml}$ (5.4 to 19.6 $\mathrm{pg} / \mathrm{ml})$.

This is the first study to evaluate the post operative course of IL 6 and their association with postoperative infection in patients with open fractures. The present study was done on open fractures and hence the increased values as trauma itself causes significant rise of IL 6 values. Kristiansson et al showed that patients with infection had a higher plasma IL 6 concentration than non-infected patients $(\mathrm{p}<0.05) 48$ hours after major surgeries. ${ }^{16}$ Sander et al also showed a corresponding decrease in IL 6 values of infected and noninfected patients after cardiac surgery, from their postoperative day 2 values. ${ }^{6}$ The overall results from this study have clearly shown that the acute phase response exist and is greater in cases of postoperative infection. Moreover, our data suggest that changes detected early in the evolution of either IL 6 or CRP may alert the surgeon to the development of insidious infection that may not have been clinically evident until then. This is crucial and could change the management for many patients. The limitation of this study includes, collection of venous blood samples on different post operative days and little higher costs of the tests.

\section{CONCLUSION}

The present clinical study of estimation of CRP and IL 6 to detect postoperative infection in patients after open fractures is an excellent diagnostic test for early detection and management of infection with most appropriate therapeutic regimen.

\section{ACKNOWLEDGEMENTS}

Author would like to thank the patients for permitting us to test the samples for the tests. I would like to thank the junior doctors, clinical microbiologists, phlebotomists, lab technical staff and the institution.

Funding: No funding sources Conflict of interest: None declared

Ethical approval: Not required

\section{REFERENCES}

1. Greidanus NV, Masri BA, Donald. Use of Erythrocyte Sedimentation Rate and $\mathrm{C}$ reactive protein level to diagnose infection before revision total knee arthroplasty. A prospective evaluation. J Bone Joint Surg. 2007;89:1409-16.

2. Hussain TM, David C. C reactive protein and Erythrocyte sedimentation rate in orthopaedics. Sring. 2002;15:13-6.

3. Kallio P, Michelsson JE. C-reactive protein in tibial fractures: Natural response to injury and operative treatment. J Bone Joint Surg. 1990;72-B:615-7.

4. Gupta R, Singh R, Soni M. C-reactive protein (CRP) as an indicator of sepsis in orthopaedic trauma. Indian J Med Sci. 2002;56(10):501-7.

5. Kragsbjerg P, Holmberg H, Vikerfors T. Serum concentrations of interleukin-6, tumour necrosis factor-alpha, and c-reactive protein in patients undergoing major operations. Eur J Surg. 1995;161(1):17-22

6. Di Cesare PE, Chang E. Serum interleukin 6 as a marker of periprosthetic infection following total hip and knee arthroplasy. J Bone Joint Surg. 2005;87:1921-7.

7. D'Auria L, Bonifati C, Mussi A, D’Agosto G, De Simone C, Giacalone B et al. Cytokines in the sera of patients with pemphigus vulgaris: interleukin-6 and tumour necrosis factor-alpha levels are significantly increased as compared with healthy subjects and correlate with disease activity. Eur Cytokine Netw. 1997;8:383-7.

8. Yamamura M, Yamada Y, Momita S, Kamihara S, Tomonaga M. Circulating interleukin-6 levels are elevated in adult T-cell leukaemia/lymphoma patients and correlate with adverse clinical features and survival. Br J Haematol. 1998;100:129-34.

9. Cruickshank AM, Fraser WD, Burns HJ, Van Damme J, Shenkin A. Response of serum interleukin-6 in patients undergoing elective surgery of varying severity. Clin Sci. 1990;79:161-5.

10. Pape HC, Remmers D, Grotz M, Kotzerke J, Von Glinski S, Van Griensven M et al. Reticuloendothelial system activity and failure in patients with multiple injuries. Arch Surg. 1999;134:421-7.

11. Pape HC, Schmidt RE, Rice J, Van Griensven M, Das Gupta R, Krettek C et al. Biochemical changes after trauma and skeletal surgery of the lower extremity: quantification of the operative burden. Crit Care Med. 2000;28:3441-8.

12. Wirtz DC, Heller KD, Miltner O, Zilkens KW, Wolff JM. Interleukin-6: a potential inflammatory marker after total joint replacement. Int Orthop. 2000;24:1946.

13. White J, Kelly M, Dunsmuir R. C-reactive protein level after total hip and total knee replacement. J Bone joint Surg Br. 1998;80:909-11.

14. Niskanen RO, Korkala O, Pammo H. Serum Creactive protein levels after total hip and knee arthroplasty. J Bone Joint Surg Br. 1996;78:431-3. 
15. Aguilar-Nascimento JE, Marra JG, Slhessarenko N, Fontes CJ. Efficacy of National Nosocomial Infection Surveillance Score, acute-phase proteins, and interleukin-6 for predicting postoperative infections following major gastrointestinal surgery. Sao Paulo Med J. 2007;125(1):34-41.

16. Kristiansson M, Soop M, Saraste L. Post-operative circulating cytokine patterns-the influence of infection. Intensive Care Med. 1993;19(7):395-400.

17. Vanderschueren S, Deeren D, Knockaert DC, Bobbaers H, Bossuyt X, Peetermans W. Extremely elevated C-reactive protein. Eur J Intern Med. 2006;17(6):430-3.

18. Kishimoto T. Interleukin-6: From basic science to medicine-40 years in immunology. Annu Rev Immunol. 2005;23:1-21.

Cite this article as: Jebaraj JPV, Rajan BE, Viswanath NA, Preethy R. A surgical study of serological markers such as $\mathrm{C}$-reactive protein and interleukin 6 in response to postoperative infection in patients with open fractures in a tertiary care hospital. Int J Res Orthop 2022;8:246-50. 